\title{
Monocytes isolated by positive and negative magnetic sorting techniques show different molecular characteristics and
} immunophenotypic behaviour [version 1; peer review: 1

\section{approved]}

\author{
Jashdeep Bhattacharjee1,2, Barun Das ${ }^{1}$, Alaknanda Mishra1 , Preeti Sahay¹, \\ Pramod Upadhyay (D) \\ ${ }^{1}$ National Institute of Immunology, New Delhi , India \\ ${ }^{2}$ Division of Gastroenterology, Hepatology and Nutrition, Children's Hospital Los Angeles, Los Angeles, CA, USA
}

\section{V1 First published: 23 Nov 2017, 6:2045 \\ https://doi.org/10.12688/f1000research.12802.1 \\ Second version: 22 Dec 2017, 6:2045 \\ https://doi.org/10.12688/f1000research.12802.2 \\ Latest published: 28 Mar 2018, 6:2045 \\ https://doi.org/10.12688/f1000research.12802.3}

\section{Abstract}

Background: Magnetic sorting of cells, based on microbead conjugated antibodies (Abs), employs positive as well as negative immunomagnetic separation methods, for isolation of a specific cell population. These microbeads are suggested to be nontoxic, biodegradable carriers conjugated to various antibodies. Isolation of cells through positive selection involves the attachment of antibody conjugated microbeads to the cells of interest, followed by their isolation in the presence of a strong magnetic field to obtain higher purity. Negative selection involves attachment of microbead conjugated antibodies to all other cell populations except the cells of interest, which remain untagged. In the present study, we compared the two methods for their effect on functional and immunophenotypic behavior of isolated CD14+ monocytes.

Methods: Peripheral blood mononuclear cells (PBMCs) were isolated from blood collected from healthy volunteers by density gradient centrifugation. Human blood derived monocytes were isolated through positive selection and negative selection, making use of the appropriate monocyte isolation kit. Monocytes were then stimulated with lipopolysaccharide (LPS) and their activation and proliferation capacity were examined. The degradation or dissociation of cellbound microbeads was also investigated.

Results: We observed an impaired LPS sensitivity as well as poor activation and proliferation capacity upon stimulation by LPS in positively sorted CD14+ monocytes as compared to negatively sorted CD14+ monocytes. The attached microbeads did not degrade and

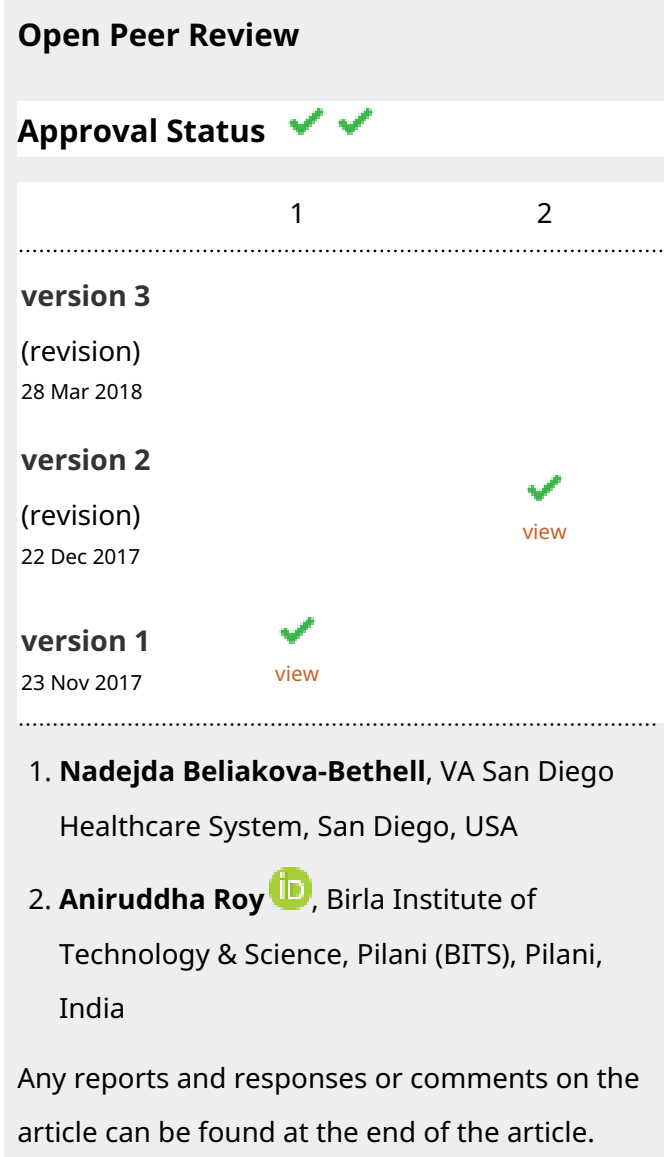


remained attached to the cells even after 6 days of culture.

Conclusions: Our results suggest that positively sorted CD14+ cells exhibit hampered functionality and may result in inaccurate analysis and observations in downstream applications. However, these cells can be used for immediate analytical procedures.

\section{Keywords}

immune-magnetic cell sorting, lipopolysaccharide sensitivity, CD14+ve monocytes

Corresponding author: Pramod Upadhyay (pkumar@nii.ac.in)

Author roles: Bhattacharjee J: Conceptualization, Investigation, Methodology, Writing - Original Draft Preparation; Das B:

Investigation, Methodology, Writing - Original Draft Preparation; Mishra A: Investigation, Methodology, Writing - Review \& Editing; Sahay P: Methodology, Writing - Original Draft Preparation; Upadhyay P: Conceptualization, Funding Acquisition, Investigation, Methodology, Supervision, Writing - Original Draft Preparation, Writing - Review \& Editing

Competing interests: No competing interests were disclosed.

Grant information: This work has been supported by the core grant received from the Department of Biotechnology, Government of India, to the National Institute of Immunology, New Delhi.

The funders had no role in study design, data collection and analysis, decision to publish, or preparation of the manuscript.

Copyright: (c) 2017 Bhattacharjee J et al. This is an open access article distributed under the terms of the Creative Commons Attribution License, which permits unrestricted use, distribution, and reproduction in any medium, provided the original work is properly cited. Data associated with the article are available under the terms of the Creative Commons Zero "No rights reserved" data waiver (CC0 1.0 Public domain dedication).

How to cite this article: Bhattacharjee J, Das B, Mishra A et al. Monocytes isolated by positive and negative magnetic sorting techniques show different molecular characteristics and immunophenotypic behaviour [version 1; peer review: 1 approved] F1000Research 2017, 6:2045 https://doi.org/10.12688/f1000research.12802.1

First published: 23 Nov 2017, 6:2045 https://doi.org/10.12688/f1000research.12802.1 


\section{Introduction}

Magnetic sorting is a common technique used to obtain a highly pure population of cells of interest from a mixed population of cells, making use of microbead conjugated antibodies against the cell surface antigen. Positive sorting involves the tagging of cells with magnetic microbead conjugated antibodies, followed by isolation of the labeled cells by placing them in a magnetic field. After positive sorting, cells that have microbead conjugated antibodies on their surface can be conveniently analyzed using flow cytometry (Füchslin et al., 2010; Miltenyi et al., 1990; Pei et al., 1998). Negative sorting involves the labeling of all cells, except the cells of interest, by incubating them in a cocktail of magnetic microbead conjugated antibodies and subsequently removing them by placing them in a magnetic field.

Cluster of differentiation 14 (CD14) are specific markers used to identify monocytic populations, and they act as a coreceptors for LPS (Guha \& Mackman, 2001). It has been suggested that positive magnetic sorting of CD14 does not trigger any signal transduction pathways or alter its functionality, since CD14 lacks a cytoplasmatic domain and such cells are reported to function in a restricted manner (Tomlinson et al., 2013). Observations made with microbead labeled cells during in vitro (Füchslin et al., 2010; Horgan et al., 2009; Semple et al., 1993) and in vivo experiments (Ribaut et al., 2008; Safarík \& Safaríková, 1999) suggested that cells post microbead attachment do not reflect the true picture and undergo altered behaviour.

We investigated the immunophenotypic behaviour and molecular characteristics of monocytes after both positive and negative sorting, by analyzing their response and proliferation to stimuli like LPS. The biodegradation profile of the attached microbeads from the CD14+ cells was also investigated.

\section{Methods}

\section{Ethical statement}

The investigation was approved (project serial number: IHEC/\#52/10) by the Institutional human ethics committee of the National Institute of Immunology, New Delhi-67, India.

\section{Isolation of PBMCs}

Experiments were performed at the National Institute of Immunology, New Delhi. $20 \mathrm{ml}$ of peripheral blood was collected from five healthy volunteers aged between 25-30 years, after obtaining their written informed consent. Blood was collected more than once from some of the volunteers and there was a minimum gap of three months between two successive sample collections. The peripheral blood mononuclear cells (PBMCs) were isolated from blood by density gradient centrifugation using $\mathrm{HiSep}^{\mathrm{TM}}$ LSM 1077 (Himedia, Mumbai; India). The obtained PBMCs were washed thrice with Dulbecco's phosphate buffered saline (Himedia, Mumbai; India) and counted using the trypan blue dye exclusion method with a hemocytometer (Rohem Industries Pvt Ltd, India).

Isolation of monocytes by magnetic activated cell sorting Human blood derived monocytes were sorted using anti-human CD14 MicroBeads (Miltenyi Biotec, Bergisch Gladbach, Germany), as per manufacturer's protocol. Similarly, monocytes were isolated by negative sorting using the monocyte isolation Kit II (Miltenyi Biotec, Bergisch Gladbach; Germany) according to manufacturer's protocol.

\section{Cell culture and antibody dissociation assay}

The positively sorted CD14 positive cells were re-suspended in RPMI 1640 medium (Himedia, Mumbai; India) supplemented with $10 \%$ fetal bovine serum (FBS) (Biological Industries, BeitHaemek Israel) and $1 \mathrm{X}$ antibiotic-antimycotic solution containing streptomycin sulphate, penicillin and amphotericin-B (Himedia, Mumbai; India), and plated at a density of $4 \times 10^{6}$ cells per well in 6 well low adherence plates (Corning, Tewksbury; USA). The cells were periodically harvested by gentle scrapping and passed through a magnetic column. Cells with and without bound microbeads (obtained in the flowthrough) were counted using a hemocytometer (Rohem Industries Pvt Ltd, India).

\section{LPS stimulation of sorted monocytes}

Monocytes separated either by positive or negative selections were re-suspended in RPMI 1640 media supplemented with $10 \%$ FBS and $1 \mathrm{X}$ antibiotic-antimycotic solution. 1 million cells/ well were plated in a 24 well cell culture plate (Corning, Tewksbury, USA) and placed in a humidified $\mathrm{CO}_{2}$ incubator (ShelLab, Cornelius; USA) at $5 \% \mathrm{CO}_{2} / 37^{\circ} \mathrm{C}$ for 24 hours. The cells were examined for adherence and thereafter stimulated with $1 \mathrm{ml}$ complete RPMI media containing 500 $\mathrm{ng} / \mathrm{ml}$ of LPS (Sigma, St. Louis; USA). Fresh media containing $500 \mathrm{ng} / \mathrm{ml}$ of LPS was replaced at each time point $(8 \mathrm{~h}, 16 \mathrm{~h}, 24 \mathrm{~h})$ for supernatant collection.

\section{Cytometric bead array}

The supernatants collected at various time points were analysed for the presence of pro- and anti-inflammatory cytokines; IL-8, IL-10, TGF- $\beta 1$ and RANTES, using cytometric bead array (CBA) (BD Biosciences, San Jose; USA) as per manufacturer's protocol. The data was recorded using BD FACSVerse (BD Biosciences, San Jose; USA) and was analysed using FCAP Array software v3.0 (BD Biosciences, San Jose; USA). The assay samples were appropriately diluted to match the detection range of the CBA kit.

\section{Live cell imaging}

The magnetic sorted monocytes were plated at a density of 1 million cells per well in a 24 well plate. After allowing the cells to adhere for 24 hours, RPMI 1640 media supplemented with $10 \%$ FBS and $1 \%$ antibiotic-antimycotic solution containing $500 \mathrm{ng} / \mathrm{ml}$ of LPS was added to the respective wells. The culture plates were then placed in Cell-IQ (CM Technologies, Tampere; Finland) and specific fields were focussed using $10 \mathrm{X}$ objective magnification. Time lapse microscopy was performed and analysed for 48 hours at 30 minutes interval using live cell imaging and software (Cell IQ Analyser, Finland).

\section{Results}

Activation and proliferation of sorted CD14+ monocytes

Sorted monocytes incubated with LPS were examined for secretion of various pro- and anti-inflammatory cytokines. The levels 
of IL-8, IL-10, TGF- $\beta 1$ and RANTES at different time points after positively and negatively isolated CD14+ monocytes were incubated with LPS were analyzed. The secretion of IL-8 was observed to be at its maximum at 8 hours in negatively sorted monocytes and at 16 hours in positively sorted monocytes (Figure 1A). The IL-8 level in negatively sorted CD14+ cells was 6 times higher than positively sorted CD14+ cells. A similar pattern was observed for secretion of RANTES (Figure 1C) and TGF- $\beta 1$ (Figure 1D), though the differences were not very pronounced. It was of significance to observe the reversed pattern for an anti-inflammatory cytokine, IL-10 (Figure 1B).

Greater secretion of the pro-inflammatory cytokines in negatively sorted CD14+ monocytes upon activation was observed, during proliferation of activated monocytes. Figure 2 shows the variation in the average number of cells per field $(487 \mu \mathrm{m} \times 364 \mu \mathrm{m})$ for positively and negatively sorted cells. Further, the progression of proliferation is shown in Video V1 for negatively sorted cells and Video V2 for positively sorted cells. Alongside Figure 2, the videos show that negatively sorted cells proliferated rapidly and extensively upon activation, and the maximum number of cells was reached after 16 hours. However, there was no clearly defined time point of maximum number of cells reached by positively sorted cells.

\section{Degradation of microbeads}

To examine the degradation of microbeads, PBMCs were labeled with anti-human CD14 antibody conjugated microbeads and sorted under a magnetic field. The sorted cells were maintained in a culture and the numbers of cells with and without microbeads were counted via flow cytometric analysis. Results of three independent samples are shown in Figure 3.

These results show the variation in percentage of cells collected in the 'flow through' of column placed in magnetic field. These were the cells from which the microbeads were either degraded or detected and cells were without microbeads. In all the three cultures we examined, the percentage of cells without microbeads was different but there was hardly any change in these percentages when the culture was continued for 6 days. This suggests that in typical culture conditions the Ab-microbeads remain bound with cells for many days.

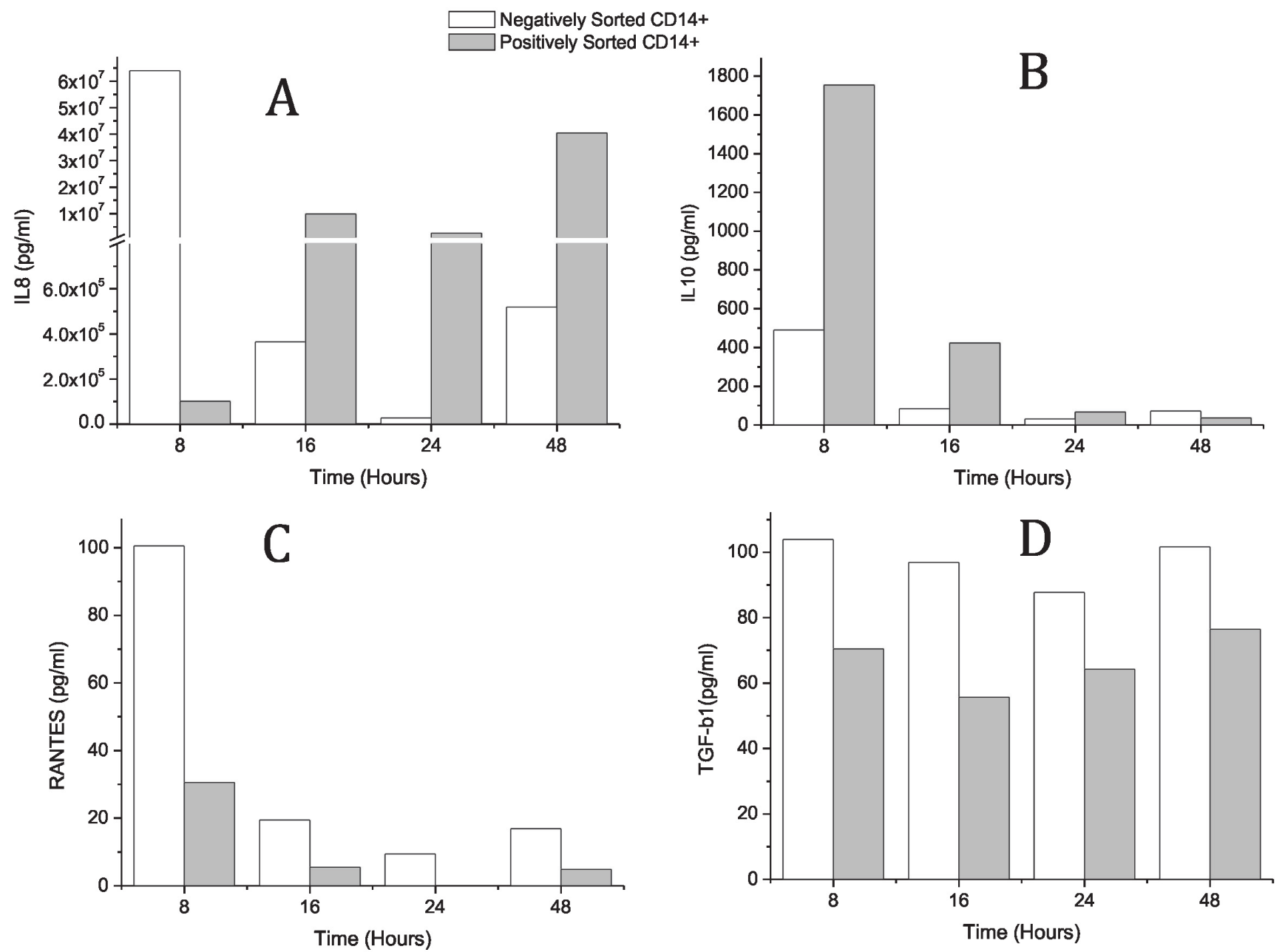

Figure 1. The levels of IL-8, IL-10, TGF- $\beta 1$ and RANTES in 5 pooled samples at different time points after positively and negatively isolated CD14+ monocytes were stimulated with LPS. 


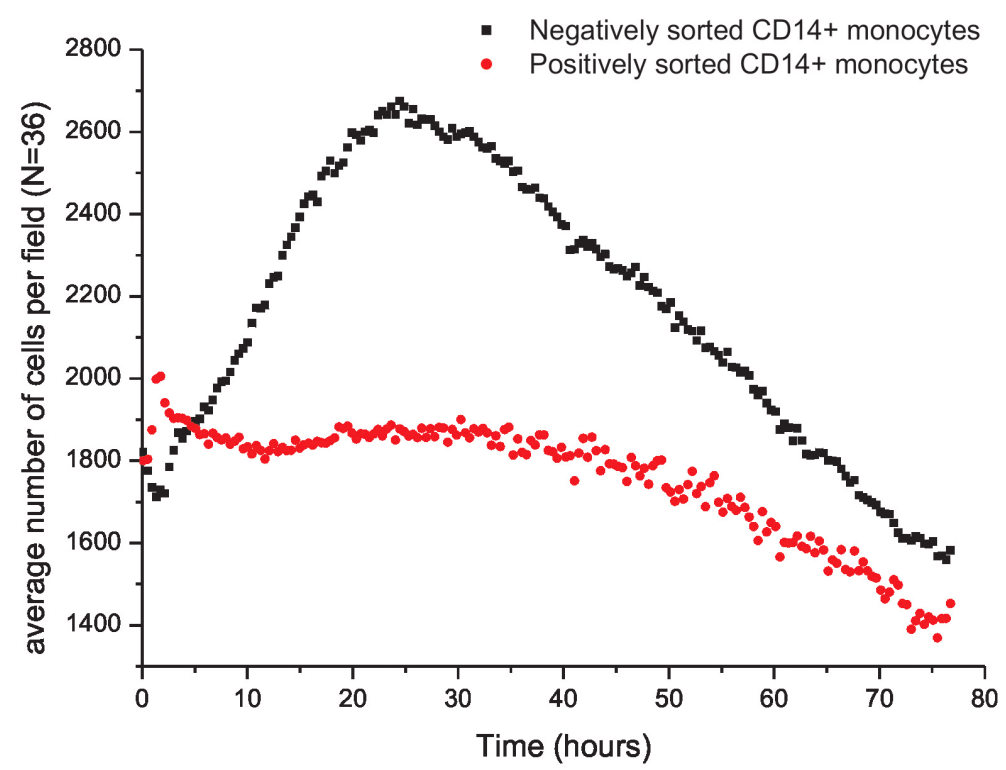

Figure 2. The changes in the average number of cells per field $(487 \mu \mathrm{mX} 364 \mu \mathrm{m})$ over time, upon stimulation by LPS in positively and negatively sorted cells.

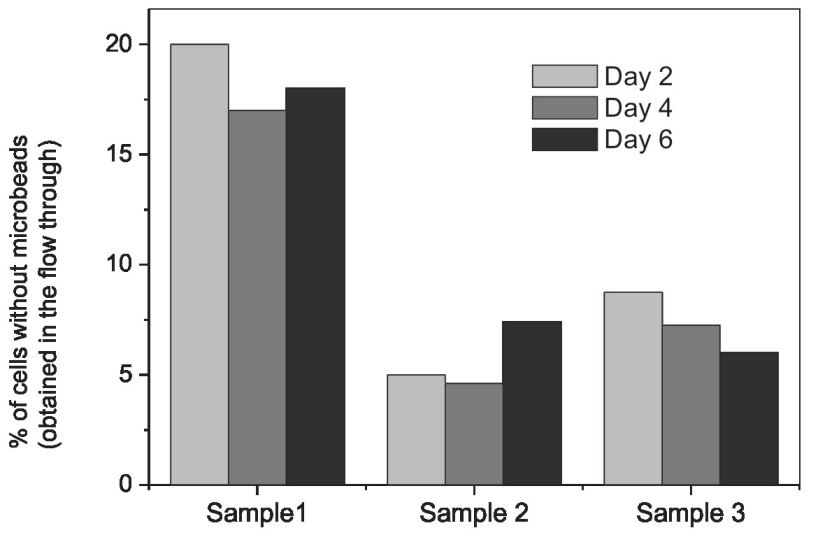

Figure 3. Variation in the percentages of CD14+ cells which do not have bound anti-CD14 microbeads when they were cultured for several days.

Dataset 1. Raw data corresponding to the results shown in Figure 1

http://dx.doi.org/10.5256/f1000research.12802.d182356

Dataset 2. Raw data corresponding to the results shown in Figure 2

http://dx.doi.org/10.5256/f1000research.12802.d182357

Dataset 3. Raw data corresponding to the results shown in Figure 3

http://dx.doi.org/10.5256/f1000research.12802.d182358

\section{Discussion}

Magnetic cell sorting for the separation of large numbers of cells according to specific cell surface markers is a technique that is commonly used (Adams et al., 2008). It is a common notion that magnetic beads are biodegradable, do not activate cells and do not affect downstream application. We have however observed that the activation and proliferation of positively sorted CD14+ cells is impaired compared to the negatively sorted cells.

The activation of monocytes by LPS is known to occur through surface CD14, which is an LPS sensing receptor. Surface CD14 plays a crucial role; it binds and transfers LPS to the surface via TLR4:MD2 complex to enable its recognition. The LPS stimulation of monocytes activates several intracellular signaling pathways which in turn activates a variety of transcription factors ultimately leading to induction of many genes encoding inflammatory cytokines (Guha \& Mackman, 2001). In short, CD14 is involved in the LPS-induced release of IL-8, which is an important pro-inflammatory cytokine (He et al., 2013).

After positively sorting CD14+ monocytes from PBMCs, the surface CD14 molecules on monocytes are blocked by antiCD14 microbeads and these CD14+ surface sites can no longer mediate the stimulation by LPS and the positively sorted CD14+ monocytes may show impaired stimulation by LPS.

In two experiments, identical numbers of CD14+ monocytes isolated by positive and negative sorting were stimulated with LPS and their activation and proliferation was monitored. Figure 1 shows that upon stimulation by LPS the negatively sorted CD14+ monocytes secreted enormous amount of IL-8 almost 
instantaneously and they exhibited acute proliferation (Figure 2). This is in accordance with the observation that IL-8 transcript is highly expressed in LPS-stimulated monocytes (Standiford et al., 1992; Suzuki et al., 2000).

The positively sorted CD14+ monocytes responded only after 24 hours, and their level of stimulation was impaired and the cells did not proliferate. This delayed and reduced stimulation by LPS is due to the CD14 independent receptors which function to direct LPS mediated cytokine secretion under conditions where the CD14 dependent pathway is blocked or non-functional (Lynn et al., 1993). There are a few LPS-associated cell surface proteins which are distinct from CD14 and these surface proteins too can bind TLRs to initiate a response (Triantafilou et al., 2001). Our results suggest that the density of these surface proteins is low compared to CD14 as lesser stimulation was observed when CD14 surface groups were blocked by Abs and secondly, the delayed stimulation indicate that most likely a different pathway was followed for their activation.

Further, the secretion of somewhat higher amount of IL-10 by positively sorted CD14+ monocytes only suggest the absence of highly inflammatory conditions upon LPS activation. The levels of RANTES and TGF- $\beta 1$ also indicate that the LPS activation of monocytes via CD14 independent receptors produces unique results which could be very different from common experimental situation.

In one such related report, the, human primary monocytes were isolated by either positive or negative immunomagnetic selection and differentiated to macrophages (Neu et al., 2013). The phagocytosis of Listeria monocytogenes (Lm) by GM-CSF-derived macrophages (GM-M) was markedly influenced by the method used for isolation of monocytes. The GM-M derived from negatively isolated monocytes showed low phagocytosis of Lm whereas GM-M generated from positively selected monocytes displayed high phagocytosis of Lm. The paper concludes that macrophages derived by ex vivo differentiation of negatively selected human primary monocytes as the most suitable model to study Lm infection of macrophages. In yet another report (Elkord et al., 2005) it was demonstrated that the human dendritic cells generated from positively isolated monocytes by anti-CD14-coated microbeads show impaired induction by LPS.

Similar findings have been made by examining the gene expression profiles of CD8+ $\mathrm{T}$ cells, $\mathrm{B}$ cells and monocytes isolated using positive selection, negative selection and FACS (Beliakova-Bethell et al., 2014).
In these reports it was not investigated further why the positively isolated monocytes were not suitable and had poor cytokines production upon stimulation. Our data suggests that in these experiments, the positively isolated monocytes were tagged permanently with anti-CD14 molecules attached with microbeads. The positively isolated CD14+ monocytes are identical with monocytes whose surface CD14 molecules have been blocked by Abs and these monocytes are known to behave differently (Delirezh et al., 2013; Elkord et al., 2005; Kim \& Kim, 2014). In this context, diverse outcome could be observed when cells positively isolated by antibody bound microbeads were used for extended culture work (Govers et al., 2012; Greish et al., 2012; Lapenna et al., 2013; Meinhardt et al., 2012).

There are two important findings from these experiments; positively isolated CD14+ monocytes have impaired LPS sensitivity and magnetic beads used in positive isolation do not degrade within days. These conclusions suggest that for most experiments, positively isolated cells are usable for analysis purpose only and should not be used for any further culture experiments.

\section{Data availability}

Dataset 1: Raw data corresponding to the results shown in Figure 1. DOI, 10.5256/f1000research.12802.d182356 (Bhattacharjee et al., 2017a)

Dataset 2: Raw data corresponding to the results shown in Figure 2. DOI, 10.5256/f1000research.12802.d182357 (Bhattacharjee et al., 2017b)

Dataset 3: Raw data corresponding to the results shown in Figure 3. DOI, 10.5256/f1000research.12802.d182358 (Bhattacharjee et al., 2017c)

\section{Competing interests}

No competing interests were disclosed.

\section{Grant information}

This work has been supported by the core grant received from the Department of Biotechnology, Government of India, to the National Institute of Immunology, New Delhi.

\section{Author details}

This work was carried out at: National Institute of Immunology, New Delhi, India. The first author, Jashdeep Bhattacharjee, has now moved to: Divison of Gastroenterology, Hepatology and Nutrition, Children's Hospital Los Angeles.

\section{Supplementary material}

Supplementary Video V1: The progression of proliferation after stimulation by LPS in negatively sorted CD14+ monocytes.

Click here to access the data.

Supplementary Video V2: The progression of proliferation after stimulation by LPS in positively sorted CD14+ monocytes. 
Adams JD, Kim U, Soh HT: Multitarget magnetic activated cell sorter. Proc Natl Acad Sci U S A. 2008; 105(47): 18165-18170.

PubMed Abstract | Publisher Full Text | Free Full Text

Beliakova-Bethell N, Massanella M, White $\mathrm{C}$, et al.: The effect of cell subset isolation method on gene expression in leukocytes. Cytometry A. 2014; 85(1): 94-104.

PubMed Abstract | Publisher Full Text | Free Full Text

Bhattacharjee J, Das B, Mishra A, et al.: Dataset 1 in: Monocytes isolated by positive and negative magnetic sorting techniques show different molecular characteristics and immunophenotypic behaviour. F1000Research. 2017a. Data Source

Bhattacharjee J, Das B, Mishra A, et al.: Dataset 2 in: Monocytes isolated by positive and negative magnetic sorting techniques show different molecular characteristics and immunophenotypic behaviour. F1000Research. 2017b. Data Source

Bhattacharjee J, Das B, Mishra A, et al.: Dataset 3 in: Monocytes isolated by positive and negative magnetic sorting techniques show different molecular characteristics and immunophenotypic behaviour. F1000Research. $2017 \mathrm{c}$. Data Source

Delirezh N, Shojaeefar E, Parvin P, et al.: Comparison the effects of two monocyte isolation methods, plastic adherence and magnetic activated cell sorting methods, on phagocytic activity of generated dendritic cells. Cell $\mathrm{J}$. 2013; 15(3): 218-223.

PubMed Abstract | Free Full Text

Elkord $\mathrm{E}$, Williams PE, Kynaston $\mathrm{H}$, et al:: Human monocyte isolation methods influence cytokine production from in vitro generated dendritic cells. Immunology. 2005; 114(2): 204-212.

PubMed Abstract | Publisher Full Text | Free Full Text

Füchslin HP, Kötzsch S, Keserue HA, et al.: Rapid and quantitative detection of Legionella pneumophila applying immunomagnetic separation and flow cytometry. Cytometry A. 2010; 77(3): 264-274.

PubMed Abstract | Publisher Full Text

Govers C, Berrevoets C, Treffers-Westerlaken E, et al:: Magnetic-activated cell sorting of TCR-engineered T cells, using tCD34 as a gene marker, but not peptide-MHC multimers, results in significant numbers of functional CD4 ${ }^{+}$and CD8 ${ }^{+}$T cells. Hum Gene Ther Methods. 2012; 23(3): 213-224.

PubMed Abstract | Publisher Full Text | Free Full Text

Greish S, Abogresha N, Abdel-Hady Z, et al.: Human umbilical cord

mesenchymal stem cells as treatment of adjuvant rheumatoid arthritis in a ra model. World J Stem Cells. 2012; 4(10): 101-109.

PubMed Abstract | Publisher Full Text | Free Full Text

Guha M, Mackman N: LPS induction of gene expression in human monocytes. Cell Signal. 2001; 13(2): 85-94.

PubMed Abstract | Publisher Full Text

He W, Qu T, Yu Q, et al:: LPS induces IL-8 expression through TLR4, MyD88,

NF-kappaB and MAPK pathways in human dental pulp stem cells. Int Endod $J$. 2013; 46(2): 128-136.

PubMed Abstract | Publisher Full Text

Horgan K, Shaw S, Boirivant M: Immunomagnetic purification of T cell

subpopulations. Curr Protoc Immunol. 2009; Chapter 7: Unit7.4.

PubMed Abstract | Publisher Full Text
Kim D, Kim JY: Anti-CD14 antibody reduces LPS responsiveness via TLR4 internalization in human monocytes. Mol Immunol. 2014; 57(2): 210-215. PubMed Abstract | Publisher Full Text

Lapenna A, B-Lynch C, Kapeni C, et al.: A simple model system enabling human $\mathrm{CD} 4^{+}$cells to undertake differentiation towards T cells. PLOS One. 2013; 8(7): e69572.

PubMed Abstract | Publisher Full Text | Free Full Text

Lynn WA, Liu Y, Golenbock DT: Neither CD14 nor serum is absolutely necessary for activation of mononuclear phagocytes by bacterial lipopolysaccharide. Infect Immun. 1993; 61(10): 4452-4461.

PubMed Abstract | Free Full Text

Meinhardt K, Kroeger I, Abendroth A, et al.: Influence of NK cell magnetic bead isolation methods on phenotype and function of murine NK cells. $J$ Immunol Methods. 2012; 378(1-2): 1-10.

PubMed Abstract | Publisher Full Text

Miltenyi S, Müller W, Weichel W, et al:: High gradient magnetic cell separation with MACS. Cytometry. 1990; 11(2): 231-238.

PubMed Abstract | Publisher Full Text

Neu C, Sedlag A, Bayer C, et al.: CD14-dependent monocyte isolation enhances phagocytosis of listeria monocytogenes by proinflammatory, GM-CSF-derived macrophages. PLoS One. 2013; 8(6): e66898.

PubMed Abstract | Publisher Full Text | Free Full Text

Pei R, Wang G, Tarsitani C, et al.: Simultaneous HLA Class I and Class II antibodies screening with flow cytometry. Hum Immunol. 1998; 59(5): 313-322. PubMed Abstract | Publisher Full Text

Ribaut C, Berry A, Chevalley S, et al:: Concentration and purification by magnetic separation of the erythrocytic stages of all human Plasmodium species. Malar J. 2008; 7: 45

PubMed Abstract | Publisher Full Text | Free Full Text

Safarík I, Safaríková M: Use of magnetic techniques for the isolation of cells. J Chromatogr B Biomed Sci Appl. 1999; 722(1-2): 33-53.

PubMed Abstract

Semple JW, Allen D, Chang W, et al:: Rapid separation of CD4+ and CD19+ lymphocyte populations from human peripheral blood by a magnetic activated cell sorter (MACS). Cytometry. 1993; 14(8): 955-960.

PubMed Abstract | Publisher Full Text

Standiford TJ, Strieter RM, Allen RM, et al:: IL-7 up-regulates the expression of IL-8 from resting and stimulated human blood monocytes. J Immunol. 1992; 149(6): 2035-2039.

PubMed Abstract

Suzuki T, Hashimoto S, Toyoda N, et al.: Comprehensive gene expression profile of LPS-stimulated human monocytes by SAGE. Blood. 2000; 96(7): 2584-2591. PubMed Abstract

Tomlinson MJ, Tomlinson S, Yang XB, et al:: Cell separation: Terminology and practical considerations. J Tissue Eng. 2013; 4: 2041731412472690. PubMed Abstract | Publisher Full Text | Free Full Text

Triantafilou K, Triantafilou M, Dedrick RL: A CD14-independent LPS receptor cluster. Nat Immunol. 2001; 2(4): 338-345.

PubMed Abstract | Publisher Full Text 


\section{Open Peer Review}

\section{Current Peer Review Status:}

\section{Version 1}

Reviewer Report 12 December 2017

https://doi.org/10.5256/f1000research.13872.r28324

(C) 2017 Beliakova-Bethell N. This is an open access peer review report distributed under the terms of the Creative Commons Attribution License, which permits unrestricted use, distribution, and reproduction in any medium, provided the original work is properly cited.

\section{Nadejda Beliakova-Bethell}

VA San Diego Healthcare System, San Diego, CA, USA

This study assesses monocyte function following isolation of these cells from total peripheral blood mononuclear cells (PBMC) using positive or negative immunomagnetic selection. It addresses an important topic, because cell isolation procedure may affect cell function and skew conclusions obtained from in vitro studies of immune cells isolated from blood. Despite a limited assessment of functions and isolation methods, this study should have an impact on selection of monocyte isolation protocol when these cells are intended for investigation of specific responses, which this study tested. The study design is appropriate and conclusions drawn are adequately supported by the results. The paper may be improved, however, by providing more details in methods, raw data and discussion, and by careful revision of citations as detailed below:

Methods:

Cytometic bead array: there are several cytometric bead arrays available for human samples (e.g. "human inflammatory cytokine kit", "human chemokine kit"). Which one was used? Legend for Figure 1 indicates that 5 samples were pooled. It would be helpful to provide details on how the pooling was done (the entire samples, equal volumes, equal proportions?) and what dilutions were made for the assay.

Live cell imaging: It appears that information in methods contradicts the data shown in Figure 2. According to the figure and supplied raw data, imaging was performed over a course of over 76 hours, while methods section states "48 hours".

Raw data:

Data for Figure 1: it might be easier to understand the data if columns were labeled by cytokine and sample (e.g. IL8 negative selection, IL8 positive selection, etc. as opposed to IL8B, IL8C, etc.) Data for Figure 2: were 36 fields for each sample for each time point individually counted, as the information on the figure indicates? Raw data appears to have only the averages. Was the distribution of counts tight, or was there high variation? Including raw data for individual field counts might be more appropriate. 
Discussion:

Another option to positively isolate monocytes is to use anti-CD33 instead of anti-CD14 coated beads. This may be more appropriate in studies that aim to measure response to LPS, when positive selection is preferred (e.g. in cases of limited sample from which sequential separation of different lymphocyte subsets is desired). It might be worthy to discuss this option.

\section{Citations:}

Several citations throughout the paper appear to be inaccurate; for example, in Introduction some citations on altered behavior of cells following microbead attachment: (1) Safarik and Safarikova is a method review, and Horgan et al. is a protocol; neither studies cell behavior; (2) Semple et al. observed no functional changes in limited tests they did; the difference that they report pertains to CD19+ vs CD19- cells, not positively isolated vs negatively isolated cells; (3) Fuchslin et al. labeled bacterial cells for their quantification in water; and Ribaut et al. labeled parasites for their isolation from infected blood for research purposes; the relevance of these two citations for the present study may be questionable. In Discussion, Adams et al. describe a special case of MACS for multitarget sort, and may not be appropriate for referencing commonality of magnetic sorting. While the results from the present study are consistent with gene expression studies by BeliakovaBethell et al. in terms of effects of positive selection, the reference to Beliakova-Bethell et al. is made following description of Neu et al. and Elkord et al. studies, stating that the findings were similar. This is not accurate because Neu et al. and Elkord et al. performed functional assessment following cell separation, while Beliakova-Bethell et al. lysed the cells immediately after isolation and did not measure cell function. Instead of the statement of similarity of findings, it might be worth pointing out that positive selection affects monocytes the most both in the short term and in the long term.

Is the work clearly and accurately presented and does it cite the current literature? Partly

Is the study design appropriate and is the work technically sound? Yes

Are sufficient details of methods and analysis provided to allow replication by others? Partly

If applicable, is the statistical analysis and its interpretation appropriate? Not applicable

Are all the source data underlying the results available to ensure full reproducibility? Partly

Are the conclusions drawn adequately supported by the results? Yes

Competing Interests: No competing interests were disclosed.

Reviewer Expertise: Virology, immunology, cell separation and flow cytometry, analysis of gene expression 


\section{I confirm that I have read this submission and believe that I have an appropriate level of expertise to confirm that it is of an acceptable scientific standard.}

\section{Author Response 18 Dec 2017}

Pramod Upadhyay, National Institute of Immunology, New Delhi , India

Thank you for providing us valuable comments. We have addressed all of them in the revised version of the manuscript.

Specifically

\section{Methods:}

Cytometic bead array: there are several cytometric bead arrays available for human samples (e.g. "human inflammatory cytokine kit", "human chemokine kit"). Which one was used? Legend for Figure 1 indicates that 5 samples were pooled. It would be helpful to provide details on how the pooling was done (the entire samples, equal volumes, equal proportions?) and what dilutions were made for the assay.

We used Cytometric Bead Array (CBA) Soluble Protein Flex Set and equal volumes of the samples were pooled. The CBA assay was performed on culture supernatants without any dilution. These details have been included in the revised manuscript.

Live cell imaging: It appears that information in methods contradicts the data shown in Figure 2. According to the figure and supplied raw data, imaging was performed over a course of over 76 hours, while methods section states "48 hours".

Live cell imaging: The imaging was performed till 76 hours and it was a mistake to mention this as 48 hours in the method section, we thank you for pointing out this anomaly and this has been corrected in the revised manuscript.

Raw data:

Data for Figure 1: it might be easier to understand the data if columns were labeled by cytokine and sample (e.g. IL8 negative selection, IL8 positive selection, etc. as opposed to IL8B, IL8C, etc.)

Suggested changes have been made.

Data for Figure 2: were 36 fields for each sample for each time point individually counted, as the information on the figure indicates? Raw data appears to have only the averages. Was the distribution of counts tight, or was there high variation? Including raw data for individual field counts might be more appropriate.

During the live cell imaging experiment images were logged and later cells were counted using the Cell-IQ Analyser software. The protocol for cell counting in the analysis software was assembled to finally provide the average number of cell count in the selected fields. The cell counts from individual fields of various images were embedded in the analysis software, thought it was possible to export these tables but due to very large number of data files we focussed only on the averages. 


\section{Discussion:}

Another option to positively isolate monocytes is to use anti-CD33 instead of anti-CD14 coated beads. This may be more appropriate in studies that aim to measure response to LPS, when positive selection is preferred (e.g. in cases of limited sample from which sequential separation of different lymphocyte subsets is desired). It might be worthy to discuss this option.

This is a good suggestion keeping in mind that the CD14 is an endogenous ligand for CD33 in monocyte-derived immature dendritic cells. It has been reported (Hiroshi Nakada et al.; J Biol Chem. 2014 Sep 5; 289(36): 25341-25350) that when monocyte-derived immature dendritic cells were stimulated with LPS in the presence of anti-CD33Ab, the production of IL-12 and phosphorylation of NF-KB decreased significantly.

Most likely the positively isolated monocytes using CD33-Ab beads would behave in a similar manner.

This possibility has been discussed in the Discussion section of the revised manuscript.

\section{Citations:}

Several citations throughout the paper appear to be inaccurate; for example, in Introduction some citations on altered behavior of cells following microbead attachment:

We once again thank the reviewer for thoroughly examining the citations; the list of references has been appropriately revised.

The differences between the findings of Beliakova-Bethell et al. and Neu et al. \& Elkord et al. have been incorporated in the revised manuscript.

Competing Interests: No competing interests were disclosed. 
The benefits of publishing with F1000Research:

- Your article is published within days, with no editorial bias

- You can publish traditional articles, null/negative results, case reports, data notes and more

- The peer review process is transparent and collaborative

- Your article is indexed in PubMed after passing peer review

- Dedicated customer support at every stage

For pre-submission enquiries, contact research@f1000.com 